\title{
Introducing a series of topical special issues of the Journal of Muscle Research and Cell Motility
}

\author{
MYBPC3 special issue editorial
}

\author{
Steven B. Marston • Mathias Gautel
}

Published online: 4 May 2012

(C) Springer Science+Business Media B.V. 2012

The Journal of Muscle Research aims to serve its readers not only by publishing original studies in muscle and motility structure and function but also by informing readers of the state of the art in muscle research and cell motility and to promote debate.

This issue of the Journal of Muscle Research and Cell Motility is the first of a series of topical special issues that combine original research with review articles related to a specific subject that we plan to publish once or twice a year. Further topical issues are being planned and we would welcome ideas for the themes to be covered in future issues.

In this issue, articles are devoted to cardiac myosinbinding protein-C. When C-protein, or myosin-binding protein-C (MyBP-C) was discovered in skeletal muscle in the early 1970s by Gerald Offer (Offer 1972; Offer et al. 1973), MyBP-C was thought to be merely a structural protein component of the thick filament. Interest in the functions of MyBP-C were galvanised when it was found that the cardiac isoform, encoded by the MYBPC3 gene on chromosome 11, was mutated in cases of hereditary hypertrophic cardiomyopathy (HCM) (Bonne et al. 1995; Watkins et al. 1995). By now, mutations in MYBPC 3 are the second-most frequently identified mutations that cause

\footnotetext{
S. B. Marston

NHLI, Myocardial Function, Imperial College London, Imperial Centre for Translational and Experimental Medicine, London W12 0NN, UK

e-mail: S.marston@imperial.ac.uk

M. Gautel ( $\square)$

Randall Division for Cell and Molecular Biophysics and Cardiovacsular Division, King's College London, Guy's Campus, New Hunt's House, London SE1 1UL, UK e-mail: Mathias.Gautel@kcl.ac.uk
}

HCM (Schlossarek et al. 2011), with carriers of a specific pathogenic mutation amounting up to $4 \%$ of the population of Indian descent (Dhandapany et al. 2009).

It has become clear that MyBP-C must play important roles in both the regulation of contractility and as the assembly of muscle myofibrils. MyBP-C is transcribed from three related genes (MYBPC1-3), which encode the slow, fast and cardiac isoforms. Like many other myofibrilassociated structural proteins, MyBP-C is composed of a series of hundred-residue domains of the intracellular immunoglobulin and fibronectin families-10-11 in the case of MyBP-C (Fürst and Gautel 1995; Otey et al. 2009). This molecular architecture is shared with the small MyBP$\mathrm{C}$ homologue, myosin-binding protein-H (Vaughan et al. 1993) and other myofibrillar proteins like myopalladin, myotilin, the myomesin isogenes and the giant scaffold and signalling proteins titin and obscurin (KontrogianniKonstantopoulos et al. 2009).

Earlier work by the laboratories of Gerald Offer, Carl Moos, Roger Starr, Rick Moss, Polly Hofmann, Criss Hartzell and others had implicated MyBP-C in contraction regulation by interactions with actin or myosin filament components, possibly dynamically modulated by phosphorylation by cAMP and calcium/calmodulin dependent protein kinases in the case of the cardiac isoform (see articles in this issue for a review of the literature). The elucidation of the primary structure of both skeletal and cardiac MyBP-C isoforms pinpointed these phosphorylation sites to the $\mathrm{N}$-terminal region within a sequence distinct from the immunoglobulin or fibronectin-like domains that form the remainder of the protein (Einheber and Fischman 1990; Fürst et al. 1992; Gautel et al. 1995). This MyBP-C motif has since been implicated as the major domain involved in contraction regulation by interactions that have been localised to both the actin and myosin 
filaments. Considerable controversy over the exact mapping of actin binding sites for cardiac MyBP-C on both regulated actin filaments as well as MyBP-C itself will need to be resolved, as discussed (Pfuhl 2012). The C-terminal domains in turn have been unequivocally associated with the anchorage of the protein to the LMM portion of myosin heavy chain (Okagaki et al. 1993; Gilbert et al. 1999; Welikson and Fischman 2002) and titin (Freiburg and Gautel 1996) and thus the thick filament backbone, allowing the $\mathrm{N}$-terminal regulatory domains the flexibility to contact myosin heads or actin.

Considerable progress has been made over the last years in understanding the molecular structure, interactions, and phosphorylation regulation of cardiac myosin-binding protein- $\mathrm{C}$ in healthy and diseased myocardium.

Most HCM-causing mutations in MYBPC3 are predicted to lead to premature stop codons and yet the truncated protein appears to be degraded in vivo and has never been identified in human heart tissue. Instead there is a consistent haploinsufficiency, even with mutations that are not expected to cause premature chain termination (Marston et al. 2009). As discussed in this issue (Marston et al. 2012; Schlossarek et al. 2012), missense mutations in $M Y B P C 3$ can cause exon-skipping and generate premature stop codons. Whilst reduction in MyBP-C content is known to affect $\mathrm{Ca}^{2+}$-regulation (Hofmann et al. 1991), there is also evidence that the missense mutation is expressed at the same time as haploinsufficiency (Harris et al. 2011), thus indicating the possibility of an additional poison peptide mechanism for the effect of mutations in MyBP-C. In contrast, (Vydyanath et al. 2012) show here that in cardiac muscle with both $M Y B P C 1$ and $M Y B P C 3$ mutations MyBP-C protein is incorporated properly within the 9 C-zone stripes, making it uncertain how such mutant proteins act to produce the symptoms of myopathy.

Equally important for understanding both the physiological as well as pathological implications of cardiac myosin-binding protein-C is its regulation by several protein kinase pathways. MyBP-C phosphorylation by PKA has been shown to be essential for normal heart function (Sadayappan et al. 2006), the sites of phosphorylation in human heart muscle have been identified and quantified (Copeland et al. 2010) and the effects of MyBP-C phosphorylation on crossbridge dynamics and the rate of stretch activation have been identified (Stelzer et al. 2006), thus providing a potential role for MyBP-C phosphorylation in the inotropic response to $\beta$-adrenergic stimulation. The potential mis-regulation of MyBP-C-linked kinase signalling in heart disease is likely an underestimated factor, as discussed here (Bardswell et al. 2012; Knöll 2012; Kuster et al. 2012). While $\mathrm{N}$-terminal fragments due to premature stop-codons do not accumulate detectably in the myocardium of HCM patients, ischaemia-reperfusion injury leads to the proteolytic cleavage of cardiac MyBP-C and the liberation of full-length protein and at least two proteolytic fragments (Jacquet et al. 2009; Govindan et al. 2012a) that show, in agreement with other studies on N-terminal fragments, tight localisation to the A-band (Govindan et al. 2012b). This suggests that such proteolytic MyBP-C fragments might exert ectopic effects on myosin regulation that could contribute to contractile failure in the reperfused heart.

While considerable progress has been made in identifying pathogenic mutations in cardiac MyBP-C and linking its phosphorylation to distinct signalling pathways, the issue of where and when it exerts its undisputed regulatory role on contractility remains controversial: interactions and actions on both myosin and actin filaments appear possible. Articles in this issue provide current expert opinions on recently accumulated evidence and provide new data on MyBP-C turnover, phosphorylation, myofibrillar interactions and pathomechanisms. Such insight into cardiac MyBP-C should also further the understanding of the skeletal muscle isoforms. We therefore hope that this special issue will serve as a catalyst for future discussion and research into this enigmatic protein, which has yet to reveal many of its secrets.

\section{References}

Bardswell SC, Cuello F, Kentish JC, Avkiran M (2012) cMyBP-C as a promiscuous substrate: phosphorylation by non-PKA kinases and its potential significance. J Muscle Res Cell Motil. doi: 10.1007/s10974-011-9276-3

Bonne G, Carrier L, Bercovici J, Cruaud C, Richard P, Hainque B, Gautel M, Labeit S, James M, Beckmann J, Weissenbach J, Vosberg H-P, Fiszman M, Komajda M, Schwartz K (1995) Cardiac myosin binding protein-C gene splice acceptor site mutation is associated with familial hypertrophic cardiomyopathy. Nat Genet 11(4):438-440

Copeland O, Sadayappan S, Messer AE, Stienen GJ, Velden J, Marston SB (2010) Analysis of cardiac myosin binding protein$\mathrm{C}$ phosphorylation in human heart muscle. J Mol Cell Cardiol 49:1003-1011

Dhandapany PS, Sadayappan S, Xue Y, Powell GT, Rani DS, Nallari $\mathrm{P}$, Rai TS, Khullar M, Soares P, Bahl A, Tharkan JM, Vaideeswar P, Rathinavel A, Narasimhan C, Ayapati DR, Ayub Q, Mehdi SQ, Oppenheimer S, Richards MB, Price AL, Patterson N, Reich D, Singh L, Tyler-Smith C, Thangaraj K (2009) A common MYBPC3 (cardiac myosin binding protein C) variant associated with cardiomyopathies in South Asia. Nat Genet 41(2):187-191

Einheber S, Fischman DA (1990) Isolation and characterization of a cDNA clone encoding avian skeletal muscle C-protein: an intracellular member of the immunoglobulin superfamily. Proc Natl Acad Sci USA 87(6):2157-2161

Freiburg A, Gautel M (1996) A molecular map of the interactions of titin and myosin-binding protein $\mathrm{C}$ : implications for sarcomeric assembly in familial hypertrophic cardiomyopathy. Eur J Biochem $235: 317-323$ 
Fürst DO, Gautel M (1995) The anatomy of a molecular giant: how the sarcomere cytoskeleton is assembled from immunoglobulin superfamily molecules. J Mol Cell Cardiol 27:951-960

Fürst DO, Vinkemeier U, Weber K (1992) Mammalian skeletal muscle C-protein: purification from bovine muscle, binding to titin and the characterization of a full length human cDNA. J Cell Sci 102:769-778

Gautel M, Zuffardi O, Freiburg A, Labeit S (1995) Phosphorylation switches specific for the cardiac isoform of myosin binding protein-C: a modulator of cardiac contraction? EMBO J 14: 1952-1960

Gilbert R, Cohen JA, Pardo S, Basu A, Fischman DA (1999) Identification of the A-band localization domain of myosin binding proteins $\mathrm{C}$ and $\mathrm{H}$ (MyBP-C, MyBP-H) in skeletal muscle. J Cell Sci 112:69-79

Govindan S, McElligott A, Muthusamy S, Nair N, Barefield D, Martin JL, Gongora E, Greis KD, Luther PK, Winegrad S, Henderson KK, Sadayappan S (2012a) Cardiac myosin binding protein- $\mathrm{C}$ is a potential diagnostic biomarker for myocardial infarction. J Mol Cell Cardiol 52(1):154-164

Govindan S, Sarkey J, Ji X, Sundaresan NR, Gupta MP, de Tombe PP, Sadayappan S (2012b) Pathogenic properties of the N-terminal region of cardiac myosin binding protein-C in vitro. J. Muscle Res. Cell Motil. doi:10.1007/s10974-012-9292-y

Harris SP, Lyons RG, Bezold KL (2011) In the thick of it: HCMcausing mutations in myosin binding proteins of the thick filament. Circ Res 108:751-764

Hofmann PA, Hartzell HC, Moss RL (1991) Alterations in $\mathrm{Ca}^{2+}$ sensitive tension due to partial extraction of C-protein from rat skinned cardiac myocytes and rabbit skeletal muscle fibers. J Gen Physiol 97:1141-1163

Jacquet S, Yin X, Sicard P, Clark J, Kanaganayagam GS, Mayr M, Marber MS (2009) Identification of cardiac myosin-binding protein $\mathrm{C}$ as a candidate biomarker of myocardial infarction by proteomics analysis. Mol Cell Proteomics 8(12):2687-2699

Knöll R (2012) Myosin binding protein C: implications for signaltransduction. J Muscle Res Cell Motil. doi:10.1007/s10974011-9281-6

Kontrogianni-Konstantopoulos A, Ackermann MA, Bowman AL, Yap SV, Bloch RJ (2009) Muscle giants: molecular scaffolds in sarcomerogenesis. Physiol Rev 89:1217-1267

Kuster DW, Bawazeer AC, Zaremba R, Goebel M, Boontje NM, van der Velden J (2012) Cardiac myosin binding protein C phosphorylation in cardiac disease. J Muscle Res Cell Motil. doi:10.1007/ s10974-011-9280-7

Marston S, Copeland O, Jacques A, Livesey K, Tsang V, McKenna WJ, Jalilzadeh S, Carballo S, Redwood C, Watkins H (2009) Evidence from human myectomy samples that MYBPC3 mutations cause hypertrophic cardiomyopathy through haploinsufficiency. Circ Res 105:219-222

Marston S, Copeland O, Gehmlich K, Schlossarek S, Carrrier L (2012) How do MYBPC3 mutations cause hypertrophic cardiomyopathy? J Muscle Res Cell Motil. doi:10.1007/s10974011-9268-3
Offer G (1972) C-protein and the periodicity in the thick filaments of vertebrate skeletal muscle. Cold Spring Harbor Symp Quant Biol 37:87-95

Offer G, Moos C, Starr R (1973) A new protein of the thick filaments of vertebrate skeletal myofibrils. Extractions, purification and characterization. J Mol Biol 74:653-676

Okagaki T, Weber FE, Fischman DA, Vaughan KT, Mikawa T, Reinach FC (1993) The major myosin-binding domain of skeletal muscle MyBP-C (C-protein) resides in the $\mathrm{COOH}-$ terminal, immunoglobulin C2 motif. J Cell Biol 123:619-626

Otey CA, Dixon R, Stack C, Goicoechea SM (2009) Cytoplasmic Igdomain proteins: cytoskeletal regulators with a role in human disease. Cell Motil Cytoskelet 66:618-634

Pfuhl M, Gautel M (2012) Structure, interactions and function of the $\mathrm{N}$-terminus of cardiac myosin binding protein $\mathrm{C}$ (MyBP-C): who does what, with what, and to whom? J Muscle Res Cell Motil. doi:10.1007/s10974-012-9291-z

Sadayappan S, Osinska H, Klevitsky R, Lorenz JN, Sargent M, Molkentin JD, Seidman CE, Seidman JG, Robbins J (2006) Cardiac myosin binding protein $\mathrm{C}$ phosphorylation is cardioprotective. Proc Natl Acad Sci USA 103(45):16918-16923

Schlossarek S, Mearini G, Carrier L (2011) Cardiac myosin-binding protein $\mathrm{C}$ in hypertrophic cardiomyopathy: mechanisms and therapeutic opportunities. J Mol Cell Cardiol 50:613-620

Schlossarek S, Schuermann F, Geertz B, Mearini G, Eschenhagen T, Carrier L (2012) Adrenergic stress reveals septal hypertrophy and proteasome impairment in heterozygous Mybpc3-targeted knock-in mice. J Muscle Res Cell Motil. doi:10.1007/s10974011-9273-6

Stelzer JE, Patel JR, Moss RL (2006) Protein kinase A-mediated acceleration of the stretch activation response in murine skinned myocardium is eliminated by ablation of cMyBP-C. Circ Res 99:884-890

Vaughan KT, Weber FE, Einheber S, Fischman DA (1993) Molecular cloning of chicken myosin-binding protein (MyBP) H (86-kDa protein) reveals extensive homology with MyBP-C (C-protein) with conserved immunoglobulin $\mathrm{C} 2$ and fibronectin type III motifs. J Biol Chem 268:3670-3676

Vydyanath A, Luther P, Gurnett CA, Marston S (2012) Axial distribution of myosin binding protein-C is unaffected by mutations in human cardiac and skeletal muscle. J Muscle Res Cell Motil. doi:10.1007/s10974-012-9286-9

Watkins H, Conner D, Thierfelder L, Jarcho JA, MacRae C, McKenna WJ, Maron BJ, Seidman JG, Seidman CE (1995) Mutations in the cardiac myosin-binding protein- $\mathrm{C}$ on chromosome 11 cause familial hypertrophic cardiomyopathy. Nat Genet 11:434-437

Welikson RE, Fischman DA (2002) The C-terminal IgI domains of myosin-binding proteins $\mathrm{C}$ and $\mathrm{H}$ (MyBP-C and MyBP-H) are both necessary and sufficient for the intracellular crosslinking of sarcomeric myosin in transfected non-muscle cells. J Cell Sci $115: 3517-3526$ 